\title{
Clinico-mycological study of onychomycosis in Botswana
}

\begin{abstract}
Background: Onychomycosis is a fungal disease of the toenails or fingernails that may include any part of the nail unit, including the matrix, bed, or plate. The causative organisms of onychomycosis are dermatophytes, Candida (yeasts), and nondermatophytic molds, associated with different clinical presentations.

Methods: A retrospective study was carried out including the patients diagnosed with onychomycosis at the National Health Laboratory, Gaborone (Botswana), from January 2009 to December 2009. The objective of the study was to find out the predominant species and most common clinical form of onychomycosis in Botswana.

Results: 59 patients were diagnosed with onychomycosis (37 females and 22 males). Trichophyton violaceum ( $T$. violaceum) was found to be the predominant species (44 patients, $74.58 \%$ ) with male to female ratio of 10:34 and the commonest clinical type was endonyx onychomycosis (45 patients, $76.27 \%$ ), followed by distal subungual onychomycosis (6 patients, 10.17\%), white superficial onychomycosis (4 patients, $6.78 \%)$ and $4(6.78 \%)$ cases of candida paronychia. Fingernail involvement was more common (48 patients, $81.35 \%$ ) compared to toenail involvement (11 patients, $18.64 \%$, all males).

Conclusion: Efforts ought to be made for the precise diagnosis and timely treatment of onychomycosis as it does not ordinarily cure by itself and can trigger more infectious lesions in other parts of the body. The treatment of onychomycosis is aimed at the eradication of the causative organism (both clinical and mycological cure). HIV status should be investigated where multiple fingernails or toenails are involved.
\end{abstract}

Keywords: Trichophyton violaceum, Trichophyton interdigitale, Trichophyton tonsurans
Volume 2 Issue 6 - 2018

\author{
Rameshwari Thakur, Avneet Singh Kalsi \\ Professor, Chaudhary Charan Singh University, India
}

Correspondence: Rameshwari Thakur, Professor, Chaudhary Charan Singh University, Meerut, U.P. U-18/75, F.F. DLF, Phase- 3, Gurugram- 122002, Harayana, India, Tel +9196 5477 5082, Email rameshwari_thakur@hotmail.com

Received: October II, 2018 | Published: November 14, 2018

\section{Introduction}

The term 'Onychomycosis' includes tinea unguium and also infection by non-dermatophyte fungi including yeasts. In $80-90 \%$ cases, the fundamental causative pathogens are Trichophyton rubrum and Trichophyton interdigitale. ${ }^{1-4}$ About $2-11 \%$ cases of onychomycosis are due to non-dermatophyte fungi such as Acremonium spp., Alternaria spp., Aspergillus spp., Fusarium spp., Scytalidium spp. and Scopulariopsis spp. About 2-10\% fungal nail infections are due to yeasts, including Candida spp. ${ }^{5-9}$ These infections are frequently under diagnosed because of poor healthcare services in underdeveloped countries. A nail has the function of protecting the distal phalanx and the surrounding tissues from the trauma. ${ }^{10}$ The prevalence of onychomycosis increases with immunosuppression (HIV/AIDS, diabetes, use of immunosuppressive therapies, cancer chemotherapy or antibiotics), increasing age, repeated injuries on nail, poor hygiene of nails and foot including occlusive foot wears, poor peripheral circulation, repeated exposure to pathogenic fungi and increasing use of health clubs for sports, swimming pools. ${ }^{11}$

Also, the prevalence of onychomycosis is increasing in Western countries, probably due to lifestyle changes and ageing of the population. About $10 \%$ of the general population, $20 \%$ of the population aged $>60$ years, up to $50 \%$ of people aged $>70$ years and up to one-third of diabetic individuals have onychomycosis. ${ }^{12}$ Onychomycosis may have a genetic predisposition, but only in a very less percentage of persons. ${ }^{13}$ The condition of nails represents the social status as observed by Gonzalez-Serva, $1990 .{ }^{14}$ Onychomycosis constitutes $50 \%$ of the nail problems. ${ }^{15}$

There are five major clinical presentations of onychomycosis

i. Distal and lateral subungual onychomycosis (DLSO)

ii. Proximal subungual onychomycosis (PSO)

iii. Superficial white onychomycosis (SWO)

iv. Endonyx onychomycosis (EO)

v. Total dystrophic onychomycosis (TDO)

\section{Methods}

A retrospective study was carried out including the patients diagnosed with onychomycosis at the National Health Laboratory, Gaborone (Botswana), from January 2009 to December 2009. A total of 165 patients either clinically diagnosed or suspicious of onychomycosis were sent to the mycology laboratory for the collection of the samples. To avoid misdiagnosis as nail psoriasis, lichen planus, contact dermatitis, nail bed tumors such as melanoma, trauma, or yellow nail syndrome, laboratory confirmation was performed. The nails were cleaned with $70 \%$ isopropyl alcohol and samples were taken. Sterile nail clippers and No. 15 surgical blades were used to collect nail clippings and subungual debris in sterile petri dishes and labeled. Potassium hydroxide $(20 \% \mathrm{KOH})$ mounts were prepared to look for the fungal elements. 
Samples were inoculated on two plates of Sabouraud's dextrose agar with chloramphenicol and Derm agar. One plate was incubated at $37^{\circ} \mathrm{C}$ and one at $25^{\circ} \mathrm{C}$ along with the Derm agar plate. Candida species were differentiated on Chromogenic candida agar. For dermatophytes, $\mathrm{KOH}$ and/or culture positive samples were considered positive. For non-dermatophyte molds, both $\mathrm{KOH}$ and culture positive samples were considered positive. Also, a second sample was taken and if both $\mathrm{KOH}$ and culture were positive, it was considered positive. Patients with only positive direct microscopy and negative culture were excluded. The criteria for the diagnosis of onychomycosis caused by non-dermatophyte molds were based on

a. Fungal elements seen in $\mathrm{KOH}$ preparation on microscopy

b. Growth of the same mold in all duplicate culture

c. No growth of a dermatophyte or yeast in all the cultures

When the filaments were seen on the light microscopy but showed a non-dermatophyte growth on culture, then another nail specimen was examined by light microscopy and culture to confirm nondermatophyte mold. Lacto phenol Cotton blue (LPCB) mounts were prepared in order to study the microscopic structures in details (Figure 4). The standard basic tests such as urease and in vitro hair perforation test were performed for the differentiation of $T$. interdigitale and $T$. rubrum.

\section{Results}

A total of 59 patients were found positive following the criteria and diagnosed with onychomycosis. The most common clinical pattern was endonyx onychomycosis (EO) i.e., 45 patients (76.27\%) (Figure 5), followed by distal subungual onychomycosis (DSO) 6 patients $(10.17 \%)$, total dystrophic onychomycosis (TDO) 5 patients, white superficial onychomycosis (WSO) 4 patients $(6.78 \%)$ and 4 patients $(6.78 \%)$ of candida paronychia (Table 1$)$. We did not found proximal subungual onychomycosis in any of our patients. All the six cases of total dystrophic onychomycosis (TDO) were $\mathrm{KOH}$ and culture negative and were not included. These patients were females in the age group of 20-40years.
Table I Clinical pattern of onychomycosis

\begin{tabular}{lll}
\hline S. No. & Clinical types & Number \& percentage \\
\hline 1 & $\begin{array}{l}\text { Distal Subungual } \\
\text { Onychomycosis (DSO) }\end{array}$ & $6(10.17 \%)$ \\
2 & $\begin{array}{l}\text { White Superficial } \\
\text { Onychomycosis (WSO) }\end{array}$ & $4(6.78 \%)$ \\
3 & $\begin{array}{l}\text { Proximal Subungual } \\
\text { Onychomycosis (PSO) }\end{array}$ & $0(0)$ \\
4 & $\begin{array}{l}\text { Endonyx Onychomycosis (EO) } \\
5\end{array}$ & $\begin{array}{l}\text { Total Dystrophic } \\
\text { Onychomycosis (TDO) }\end{array}$ \\
6 & $\begin{array}{l}\text { Candida paronychia } \\
\text { Total }\end{array}$ & $4(6.78 \%)$ \\
\hline
\end{tabular}

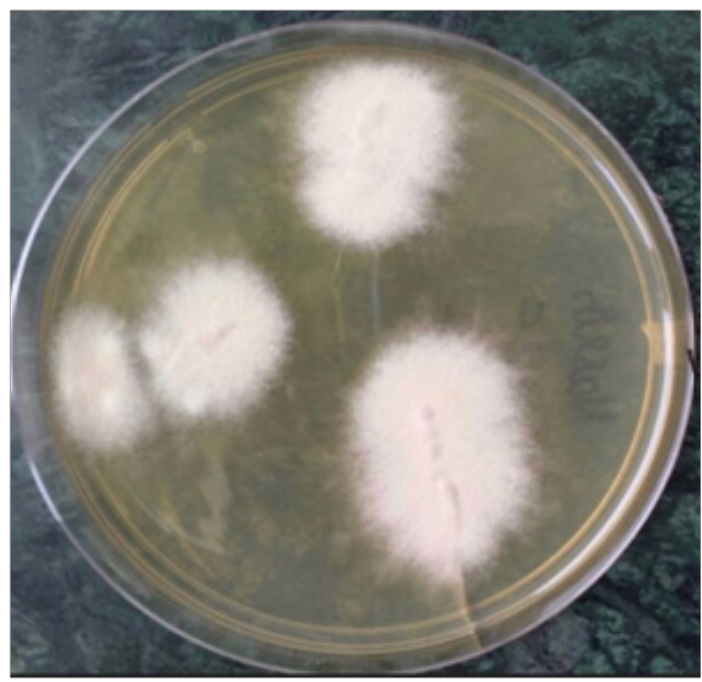

Figure I Trichophyton interdigitale.

Table 2 Distribution of onychomycosis pathogens by age groups and fingernails/toenails involvement

\begin{tabular}{|c|c|c|c|c|c|c|c|c|c|c|}
\hline \multirow{2}{*}{$\begin{array}{l}\text { Age group } \\
\text { (in years) }\end{array}$} & \multicolumn{2}{|l|}{ T. violaceum } & \multicolumn{2}{|c|}{ T. interdigitale } & \multicolumn{2}{|c|}{ T. tonsurans } & \multicolumn{2}{|c|}{$\begin{array}{l}\text { Non-dermatophytic } \\
\text { molds }\end{array}$} & \multicolumn{2}{|c|}{ Candida albicans } \\
\hline & Fingernails & $\begin{array}{l}\text { Toe- } \\
\text { nails }\end{array}$ & $\begin{array}{l}\text { Finger- } \\
\text { nails }\end{array}$ & Toenails & $\begin{array}{l}\text { Finger- } \\
\text { nails }\end{array}$ & Toenails & $\begin{array}{l}\text { Finger- } \\
\text { nails }\end{array}$ & Toenails & Fingernails & Toenails \\
\hline $0-15$ & 04 (6.77\%) & - & - & $0 \mathrm{I}(\mathrm{I} .69 \%)$ & - & - & - & - & 이 (I.69\%) & - \\
\hline $16-30$ & II (I8.64\%) & - & - & $0 \mathrm{I}(\mathrm{I} .69 \%)$ & - & 이 (I.69\%) & - & $0 \mathrm{I}(\mathrm{I} .69 \%)$ & 02 (3.38\%) & - \\
\hline $31-45$ & $10(16.94 \%)$ & - & - & $0 \mathrm{I}(\mathrm{I} .69 \%)$ & - & - & - & 02 (3.38\%) & - & - \\
\hline $46-60$ & 07 (I I.86\%) & - & - & - & - & - & - & $0 \mathrm{I}(1.69 \%)$ & - & - \\
\hline$>61$ & 12 (20.33\%) & - & - & - & - & - & - & 02 (3.38\%) & OI (I.69\%) & OI (I.69\%) \\
\hline
\end{tabular}


Table 3 Onychomycosis pathogens

\begin{tabular}{llll}
\hline Species & $\begin{array}{l}\text { Number of } \\
\text { isolates }\end{array}$ & Male: Female & Percentage \\
\hline T. violaceum & 44 & $10: 34$ & 74.58 \\
T. interdigitale & 3 & $3: 00$ & 5.09 \\
T. tonsurans & $\mathrm{I}$ & $1: 00$ & 1.69 \\
Aspergillus sp. & 3 & $3: 00$ & 5.09 \\
Fusarium sp. & 2 & $2: 00$ & 3.39 \\
Alternaria sp. & 1 & $1: 00$ & 1.69 \\
Candida albicans & 4 & $0: 04$ & 6.78 \\
Candida parpsilosis & 1 & $1: 00$ & 1.69 \\
Total & 59 & $21: 38$ & 100 \\
\hline
\end{tabular}

Out of total 59 patients with onychomycosis, 37 patients $(62.7 \%)$ were females and 22 patients $(37.2 \%)$ were males (Table 2). Fingernail involvement was more common (48 patients, $81.3 \%$ ) compared to toenail involvement (11 patients, $18.64 \%$, all males). In the age group of $0-15 y e a r s$, we found four cases of tinea unguium of fingernails due to $T$. violaceum (Figures 2,4,6,7,8) and one case of toenail involvement due to $T$. interdigitale (Figure 1). In three HIV positive females, fingernails were bilaterally involved with culture positive for T. violaceum (Figure 9). 34 (57.62\%) females and $10(16.94 \%)$ males had onychomycosis of the fingernails due to $T$. violaceum (Table 3). Out of four male patients, onychomycosis of toenails due to $T$. interdigitale was found in 3 patients (5\%) (Table 3 ) and $T$. tonsurans (Figure 3 ) was insolated in 1 patient $(1.69 \%)$. Nondermatophyte molds were isolated from the toenails of $6(10 \%)$ male patients and candida from $1(1.69 \%)$ male patient. Onychomycosis of the fingernails due to candida was isolated in $3(5.08 \%)$ females and of toenail in $2(3.38 \%)$ male patients (Table 2). HIV status was known in 15 patients only. One HIV positive female patient was on azidothymidine and had melanonychia along with tinea unguium of fingernails due to T. violaceum (Figure 10). Distribution of tinea unguium of the fingernails due to $T$. violaceum as shown in Figure 11 , shows the highest prevalence among the age group 16-30 years and second highest among 31-45years age group. These possibly correspond to the highest prevalence of HIV/AIDS among these age groups.
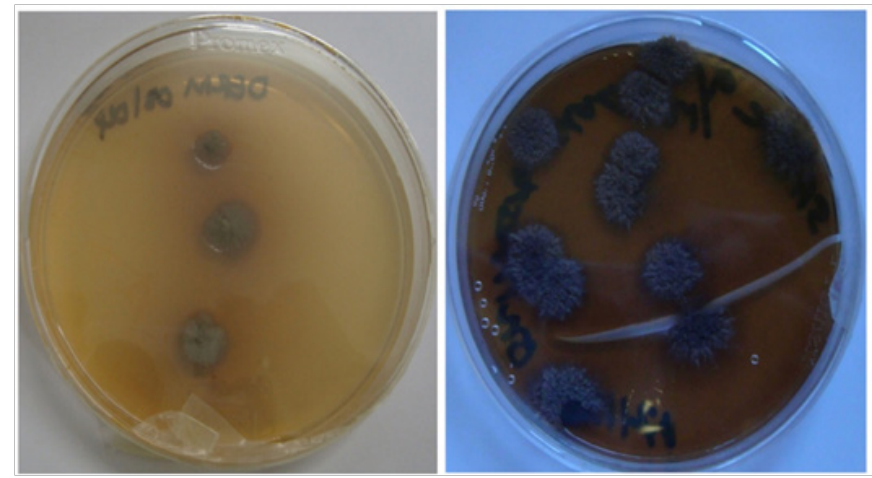

Figure 2 (a) Colonies of T. violaceum with waxy surface. (b) Verrucose colonies of $T$. violaceum with deep violet pigment.

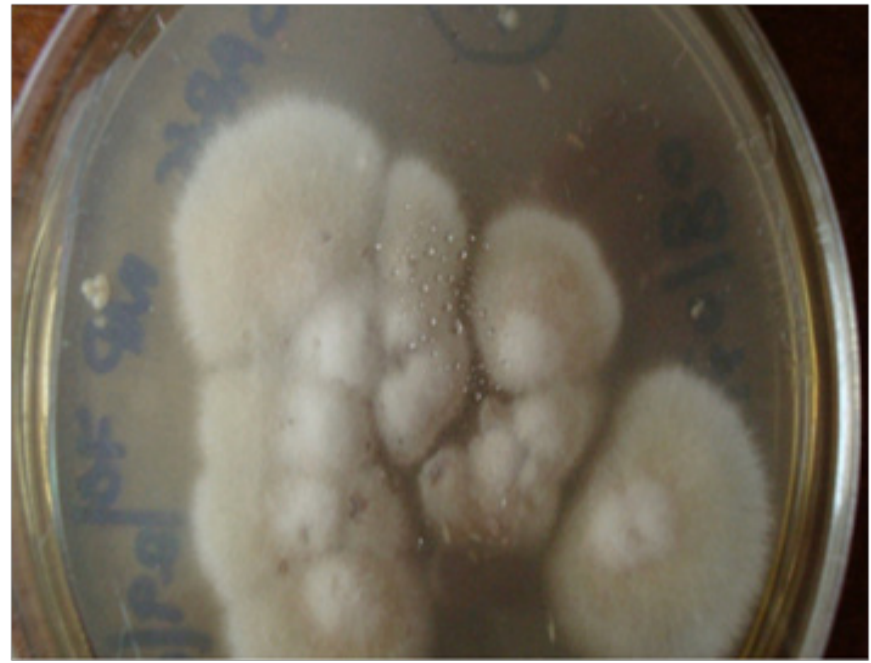

Figure 3 Trichophyton tonsurans.

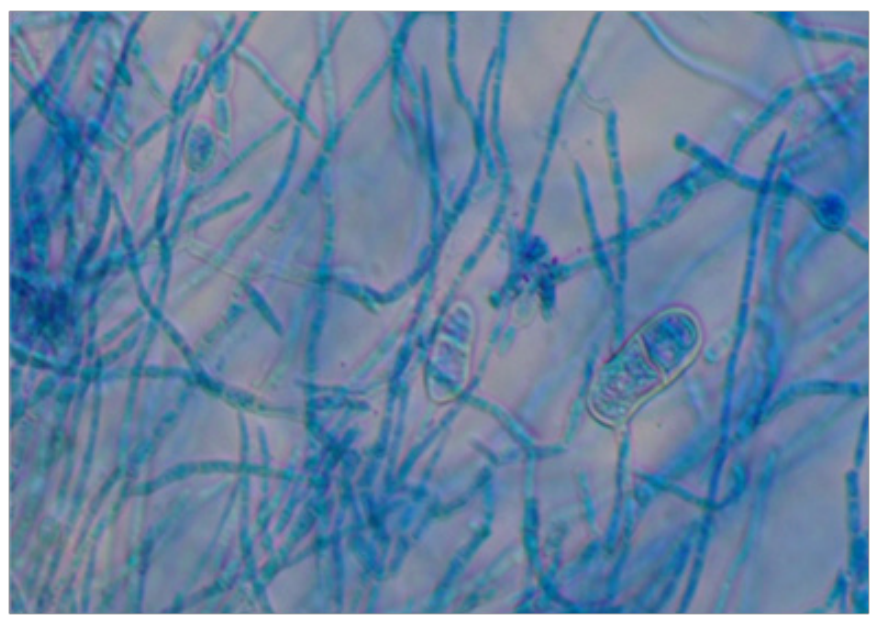

Figure 4 Trichophyton violaceum (Lacto Phenol Cotton Blue mount). Irregularly branched hyphae with intercalary chlamydoconidia and clavate two-celled macroconidia. Magnification X400.

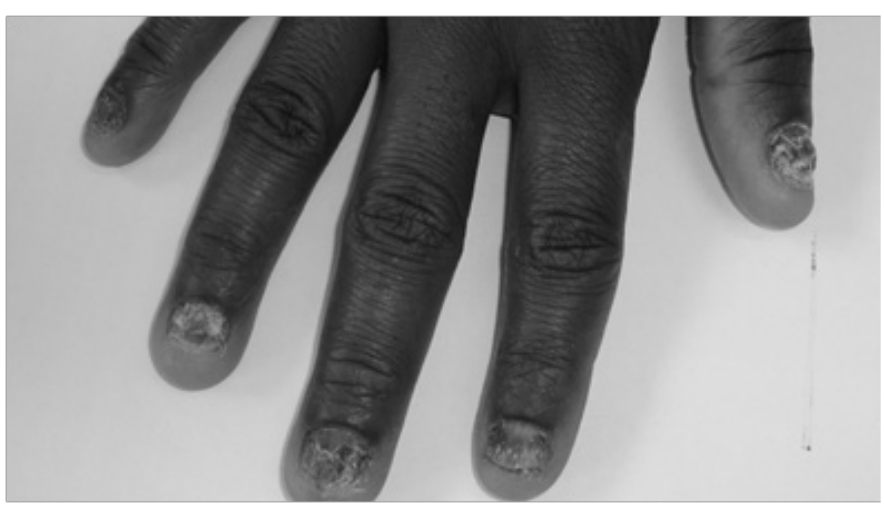

Figure 5 Endonyx onychomycosis in a HIV positive male. 


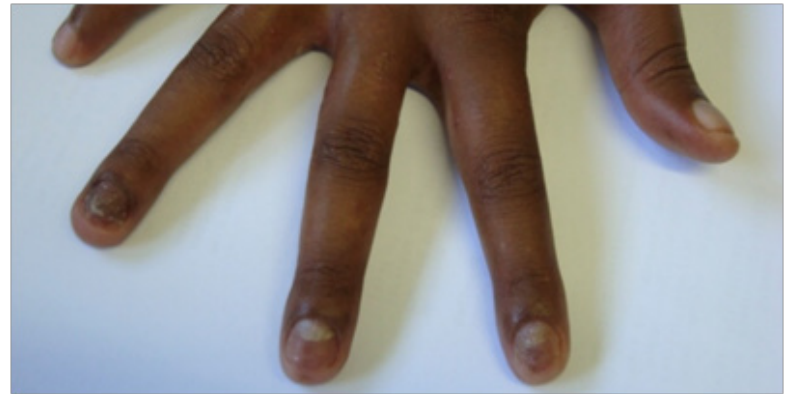

Figure 6 Tinea unguium. T. violaceum was isolated.

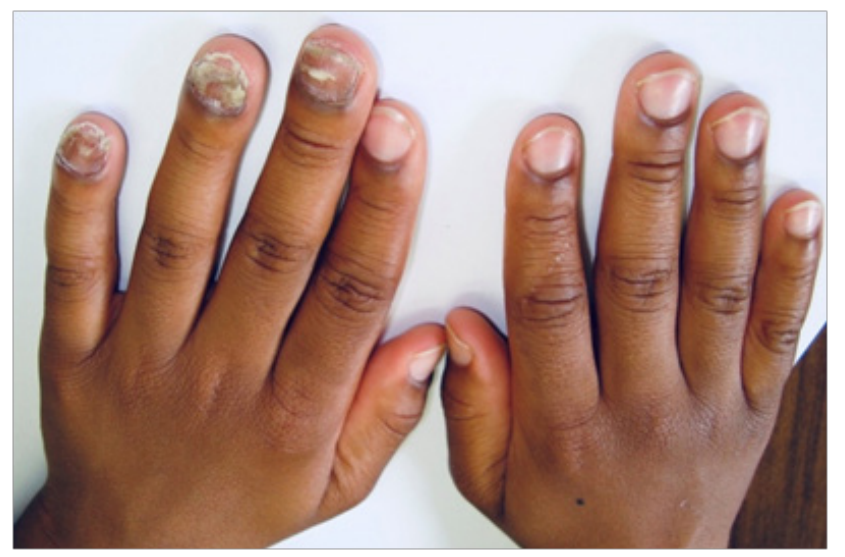

Figure 7 A 10-years old boy with tinea unguium (endonyx type) of left hand affecting nails of middle, ring and little fingers.

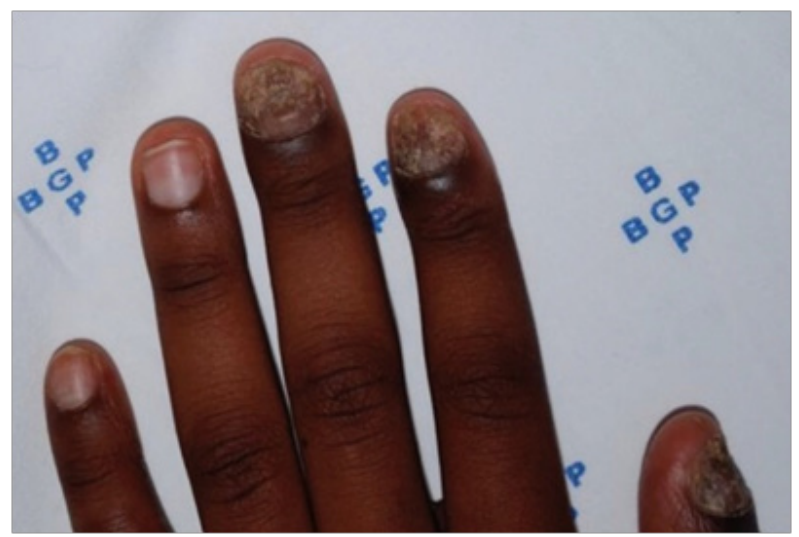

Figure 8 Tinea unguium of the left hand in a I4-years old male, affecting nails of thumb, index and middle fingers.

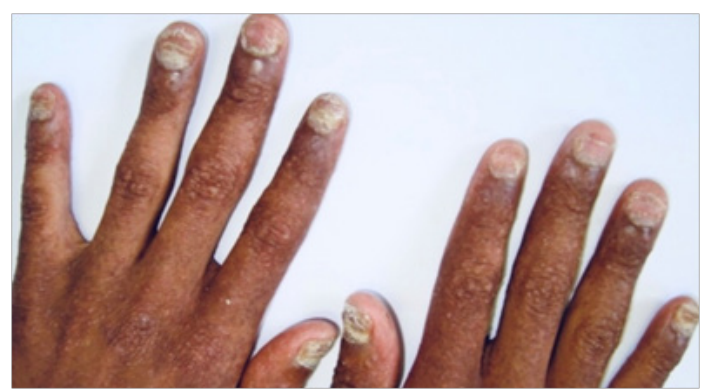

Figure 9 Tinea unguium (endonyx type) of all the nails in a HIV positive 22 years old female.

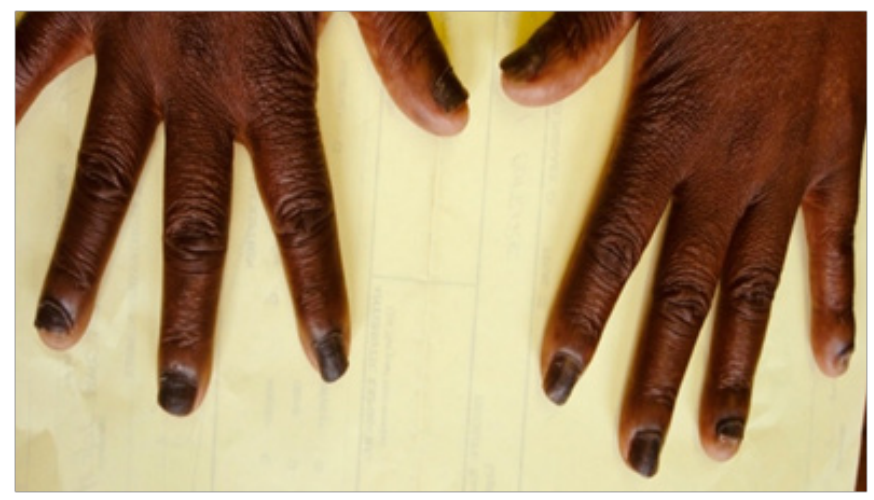

Figure 10 Tinea unguium of all the fingernails with melanonychia in a HIV positive 5 lyears old female. She was on azidothymidine.

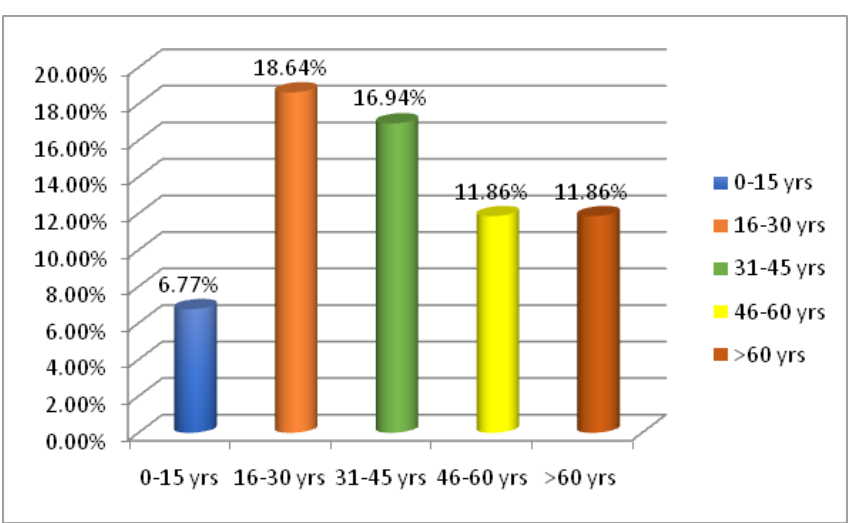

Figure I I Bar diagram of onychomycosis due to T. violaceum among different age groups.

\section{Discussion}

Onychomycosis is caused by dermatophytes, non-dermatophyte molds (NDMs), and yeasts. Dermatophytes are the main causative agent in temperate climates, whereas Candida and non-dermatophyte molds in tropical regions. ${ }^{16}$ It is traditionally a disease of the elderly. ${ }^{17} \mathrm{It}$ has a significant impact on patient's life and may cause psychological, social or employment related problems. ${ }^{18}$

Overall, dermatophytes are most commonly implicated, accounting for $90 \%$ of toenail infections and $50 \%$ of fingernail infections, and T. rubrum is responsible for most cases worldwide. ${ }^{19}$ But scenario here in Botswana differs to a great extent from other geographical locations. In our study, we found $T$. violaceum as the predominant species accounting for $100 \%$ fingernail infections.

Onychomycosis is one of the early manifestations of HIV infection with a prevalence of $15-40 \%{ }^{20}$ It is four times more common in HIV infected individuals than in the general population, which is reported to be up to $23 \%$ when their T-lymphocytes count is as low as $400 / \mathrm{mm}^{3}$ (normal range: $1200-1400 / \mathrm{mm}^{3}$ ), usually affecting all finger-nails and toe-nails. ${ }^{21-23}$ Multiple nail involvement, isolation of both common and rare species, and resistance to treatment are the characteristics of onychomycosis in HIV. ${ }^{20}$ Proximal subungual onychomycosis is usually an indication of HIV infection. ${ }^{24-26}$ Botswana has the secondhighest HIV infection rate in the world after Swaziland, with one in three adults infected. Females were infected more than males $(21$ males, 38 females), this can be related to the high prevalence of HIV 
in females $(28.9 \%)$ as compared to males $(18.9 \%)$ during the period 2007-2009. ${ }^{27}$ Population migration during the world wars led to the distribution of T. rubrum from its source regions to the new places like Europe and America. ${ }^{28,29}$

The first documented case of onychomycosis in US has been reported in 1928. ${ }^{28,30}$ The prevalence of tinea pedis and onychomycosis increased in $20^{\text {th }}$ century during the World War II and the Korean and Vietnam wars and due to the occlusive footwear and population migration. Vietnam war resulted in increased prevalence of $T$. rubrum worldwide. ${ }^{31}$ But in Botswana, $74.58 \%$ cases of onychomycosis are due to $T$. violaceum. The authors did not report a single case due to $T$. rubrum. The involvement of the fingernails is the most common. The Asian Achilles Survey conducted in the late 1990s confirmed that the prevalence of onychomycosis is relatively low in Asian countries. ${ }^{32}$

Onychomycosis in children was thought to be more frequent in fingernails due to Candida spp..$^{33}$ But we found T. violaceum 4 (6.77\%) to be the predominant species for fingernail infection in children (up to 15 years of age) as well. The reason for low frequency of onychomycosis in children is due to faster nail growth, lower incidence of tinea pedis and less exposure to spores, less chances of nail injuries and smaller surface area. Patients with Down's syndrome have more chances of onychomycosis as studied in Mexico. ${ }^{34}$ High prevalence of onychomycosis in children could be either due to high prevalence of tinea capitis ${ }^{27}$ and/or HIV. Other reasons include fungal infections in the other family members, pre-existing tinea pedis, physical activities, trisomy 21 , obesity and diabetes mellitus. ${ }^{35}$ In a study held at Colorado, $46.8 \%$ children suffered from onychomycosis, with high prevalence at the age group between $6-10 .{ }^{36}$ High prevalence of HIV among the population predisposes to increased fungal infections due to low immunity. One study has announced an evidently higher percentage of onychomycosis in HIV-positive patients with respect to general patients visiting dermatologic centers. ${ }^{37}$ Goodman et al observed that the pervasiveness of dermatophytosis was four times higher among HIV infected people. ${ }^{38}$

Endonyx type was the most common clinical form of onychomycosis in our study followed by distal subungual onychomycosis (DSO) and total dystrophic onychomycosis (TDO). In this, patients presents with milky-white discoloration of the nail plate without hyperkeratosis or onycholysis. The dermatophyte responsible for endothrix type of hair invasion usually invades the nail..$^{39,40} \mathrm{We}$ found very less cases of onychomycosis due to NDMs (10.16\%) and Candida albicans $(8.47 \%)$, this is possibly due to the fact that NDMs and Candida are the causative agents in tropical regions, whereas Botswana has a semi-arid climate with short rainy season. NDMs accounted for $100 \%$ toenail infections, whereas Candida albicans accounted for $80 \%$ fingernail infection and $20 \%$ toenail infection.

The treatment of onychomycosis is aimed at eradication of the causative organism and return to a normal appearance of a nail. Treatment of onychomycosis relies on factors like the patient's age and inclination of regimen (daily, weekly or monthly pulse therapy), the contaminating fungus and number of nails involved, level of nail association, whether toenails or fingernails are influenced and whether different medications are being taken. ${ }^{41}$

The first line systemic treatment for onychomycosis is griseofulvin, itraconazole, fluconazole and terbinafine. ${ }^{42}$ An alternative topical treatment with $8 \%$ ciclopirox, $5 \%$ amorolfine and $40 \%$ urea plus $1 \%$ bifonazole can also be given but these are generally ineffective, with a failure rate of more than $60 \%$, due to significant nail plate disease or nail matrix involvement. Concomitant nail debridement further increases the cure rates. Lasers and photodynamic therapies are also available. The long term cure is difficult to achieve in patients with onychomycosis. ${ }^{42}$ Relapses and/or recurrences are common in these patients. The relapses are less common in patients treated with terbinafine compared to itraconazole. ${ }^{42}$ Long term and continued treatment with efinaconazole $10 \%$ topical solution was found to be very effective and appeared to prevent relapses. ${ }^{43}$ Efforts should be made for the accurate diagnosis and timely treatment of toenail onychomycosis as it does not typically cure itself and can trigger more infectious lesions in other parts of the body ${ }^{44}$ According to Mehregan and Gee treatment of onychomycosis should never be started without proper diagnosis of fungal infection. ${ }^{45}$

\section{Conclusion}

Efforts ought to be made for the precise diagnosis and timely treatment of onychomycosis as it does not ordinarily cure by itself and can trigger more infectious lesions in other parts of the body. The treatment of onychomycosis is aimed at the eradication of the causative organism (both clinical and mycological cure). HIV status should be investigated where multiple fingernails or toenails are involved.

\section{Statement of ethics}

The study was conducted in accordance with research ethics.

\section{Acknowledgements}

Authors thank all the individuals who contributed to this study. No funding was received for the study.

\section{Conflict of interest}

The authors declare there is no conflict of interest.

\section{References}

1. Gupta AK, Ryder JE, Baran R, et al. Non-dermatophyte onychomycosis. Dermatol Clin. 2003;21(2):257-268.

2. Seebacher C, Brasch J, Abeck D, et al. Onychomycosis. Mycoses. 2007;50(4):321-327.

3. Loo DS. Onychomycosis in the elderly: drug treatment options. Drugs Aging. 2007;24(4):293-302.

4. Foster KW, Ghannoum MA, Elewski BE. Epidemiologic surveillance of cutaneous fungal infection in the United States from 1999 to 2002. $\mathrm{J} \mathrm{Am}$ Acad Dermatol. 2004;50(5):748-752.

5. Niewerth M, Korting HC. Management of onychomycoses. Drugs. 1999;58(2):283-296.

6. Gupta AK, Ricci MJ. Diagnosing onychomycosis. Dermatol Clin. 2006;24(3):365-369.

7. Finch JJ, Warshaw EM. Toenail onychomycosis: current and future treatment options. Dermatol Ther. 2007;20(1):31-46.

8. Vander SMR, Hossain MA, Ghannoum MA. Cutaneous infections dermatophytosis, onychomycosis, and tinea versicolor. Infect Dis Clin North Am. 2003;17(1):87-112. 
9. Effendy I, Lecha M, Feuilhade de Chauvin M, et al. Epidemiology and clinical classification of onychomycosis. J Eur Acad Dermatol Venereol. 2005;19(Suppl 1):8-12.

10. Samman PD. Anatomy and physiology. In: Samman PD, Fenton DA, editors. The nails in disease. 4th ed. London: Heinemann; 1986:1.

11. Elewski BE. Onychomycosis: Pathogenesis, Diagnosis, and Management. Clin Microbiol Rev. 1998;11(3):415-429.

12. Thomas J, Jacobson GA, Narkowicz CK, et al. Toenail onychomycosis: an important global disease burden. J Clin Pharm Ther. 2010;35(5):497519.

13. Elewski BE, Tosti A. Risk Factors and Comorbidities for Onychomycosis: Implications for Treatment with Topical Therapy. J Clin Aesthet Dermatol. 2015;8(11):38-42.

14. Gonzalez-Serva. A: Structure and function. In: Scher RK, Daniel CR III, editors. Nails: Therapy, Diagnosis, Surgery. Philadelphia: WB Saunders; 1990. $11 \mathrm{p}$

15. Faergemann J, Baran R. Epidemiology, Clinical presentation and diagnosis of onychomycosis. Br J Dermatol. 2003;149(Suppl 65):1-4.

16. Havlickova B, Czaika VA, Friedrich M. Epidemiological trends in skin mycoses worldwide. Mycoses. 2008;51(Suppl 4):2-15.

17. Raran R. The nail in the elderly. Clin Dermatol. 2011;29(1):54-60.

18. Elewski BE. Onychomycosis: treatment, quality of life, and economic issues. Am J Clin Dermatol. 2000;1(1):19-26.

19. Kaur R, Kashyap B, Bhalla P. Onychomycosis- epidemiology, diagnosis and management. Indian J Med Microbiol. 2008;26(2):108-116.

20. Surjushe A, Kamath R, Oberai C, et al. A clinical and mycological study of onychomycosis in HIV infection. Indian J Dermatol Venereol Leprol. 2007;73(6):397-401.

21. Hogan MT. Cutaneous infections associated with HIV/AIDS. Dermatol Clin. 2006;24(4):473-495.

22. Vander SMR, Hossain MA, Ghannoum MA. Cutaneous infections dermatophytosis, onychomycosis, and tines versicolor. Infect Dis Clin North Am. 2003;17(1):87-112.

23. Baran R, Hay RJ, Garduno JI. Review of antifungal therapy, part II: treatment rationale, including specific patient populations. J Dermatolog Treat. 2008;19(3):168-175.

24. Tosti A, Hay R, Arenas-Guzman R. Patients at risk of onychomycosisrisk factor identification and active prevention. J Eur Acad Dermatol Venereol. 2005;19(Suppl 1):13-16.

25. Faergemann J, Baran R. Epidemiology, clinical presentation and diagnosis of onychomycosis. Br J Dermatol. 2003;149(Suppl 65):1-4.

26. Nandedkar-Thomas MA, Scher RK. An update on disorders of the nails. $J$ Am Acad Dermatol. 2005;52(5):877-887.

27. UNAIDS. UNAIDS report on the global AIDS epidemic 2010- The global reference book on the AIDS epidemic and response. UNAIDS; 2010. Accessed 15 January, 2012.
28. Charif MA, Elewski BE. A historical perspective on onychomycosis. Dermatol Ther. 1997;3:43-45.

29. Weidman FD. The laboratory aspects of dermatophytosis. Arch Derm Syphilol. 1927;15(4):415-450.

30. Salgo PL, Daniel CR, Gupta AK, et al. Onychomycosis disease management. Med Cross: Deb, Peer Ex Ins Med. 2003;4:1-17.

31. Elewski BE. Tinea pedis and tinea manuum. In: Demis JD, editor. Clinical Dermatology. Philadelphia: JB Lippincott Co;1993:1-10.

32. Bramono K. The Asian Achilles Survey. Presented in the $6^{\text {th }}$ Asian Dermatological Congress, Bangkok. November, 2001.

33. Kalter DC, Hay RJ. Onychomycosis due to Trichophyton soudanense. Clin Exp Dermatol. 1988;13(4):221-227.

34. Córdova ME, Arenas R, López C, et al. Down's Syndrome. Frequency and characteristics of onychomycosis of the feet. Dermatología Rev Mex. 2000;44(1):5-9.

35. Nenoff P, Krüger C, Schaller J, et al. Mycology-an update part 2: dermatomycoses: clinical picture and diagnostics. $J$ Dtsch Dermatol Ges. 2014;12(9):749-777.

36. Young LS, Arbuckle HA, Morelli JG. Onychomycosis in the Denver pediatrics population, a retrospective study. Pediatr Dermatol. 2014;31(1):106-108.

37. Gupta AK, Taborda P, Taborda V, et al. Epidemiology and prevalence of onychomycosis in HIV-positive individuals. Int $J$ Dermatol. 2000;39(10):746-753.

38. Goodman DS, Teplitz ED, Wishner A, et al. Prevalence of cutaneous disease in patients with acquired immunodeficiency syndrome (AIDS) or AIDS-related complex. J Am Acad Dermatol. 1987;17(2 Pt 1):210-220.

39. Baran R, Dawber RPR, Tosti A, et al. Onychomycosis and its treatment. In: A Text Atlas of Nail Disorders: Diagnosis and Treatment. London: Martin Dunitz; 1996;3:35-38.

40. Kalter DC, Hay RJ. Onychomycosis due to Trichophyton soudanense. Clin Exp Dermatol. 1988;13(4):221-227.

41. Gupta AK, Daniel CR. Factors that may affect response of onychomycosis to oral antifungal therapy. Aust J Dermatol. 1998;39(4):222-224.

42. Piraccini BM, Sisti A, Tosti A. Long-term follow-up of toenail onychomycosis caused by dermatophytes after successful treatment with systemic antifungal agents. J Am Acad Dermatol. 2010;62(3):411-414.

43. Elewski BE, Tosti A, Lin T. Efinaconazole 10\% topical solution: Case review of onychomycosis patients who were completely cured at week 24 . Skin Appendage Disord. 2018;4(2):67-70.

44. Thomas J, Jacobson GA, Narkowicz CK, et al. Toenail onychomycosis: an important global disease burden. J Clin Pharm Ther. 2010;35(5):497519.

45. Mehregan DR, Gee SL. The cost-effectiveness of testing for onychomycosis versus empiric treatment of onychodystrophies with oral antifungal agents. Cutis. 1999;64(6):407-410. 